\title{
Compliance of Pharmacotherapy with GOLD Guidelines: A Longitudinal Study in Patients with COPD
}

This article was published in the following Dove Press journal: International Journal of Chronic Obstructive Pulmonary Disease

\author{
Fabian A Grewe $\mathbb{D}^{\prime}$ \\ Noriane A Sievi (D) \\ Matteo Bradicich' \\ Maurice Roeder' \\ Thomas Brack $\mathbb{D}^{2}$ \\ Martin H Brutsche 3 \\ Martin Frey (iD ${ }^{4}$ \\ Sarosh Irani ${ }^{5}$ \\ Jörg D Leuppi $\mathbb{1 D}^{6}$ \\ Robert Thurnheer (D) $^{7}$ \\ Christian F Clarenbach $\mathbb{D}^{\prime}$ \\ Malcolm Kohler ${ }^{1,8}$ \\ 'Pulmonary Division, University Hospital \\ Zurich, Zurich, Switzerland; ${ }^{2}$ Pulmonary \\ Division, Cantonal Hospital of Glarus, \\ Glarus, Switzerland; ${ }^{3}$ Pulmonary Division, \\ Cantonal Hospital of St. Gallen, \\ St. Gallen, Switzerland; ${ }^{4}$ Pulmonary \\ Division, Clinic Barmelweid, Erlinsbach, \\ Switzerland; ${ }^{5}$ Pulmonary Division, \\ Cantonal Hospital of Aarau, Aarau, \\ Switzerland; ${ }^{6}$ University Department of \\ Medicine, Cantonal Hospital Baselland and \\ University of Basel, Basel, Switzerland; \\ ${ }^{7}$ Pulmonary Division, Cantonal Hospital of \\ Münsterlingen, Münsterlingen, Switzerland; \\ ${ }^{8}$ Zurich Centre for Integrative Human \\ Physiology, University of Zurich, Zurich, \\ Switzerland
}

Correspondence: Malcolm Kohler

Pulmonary Division, University Hospital

Zurich, Raemistrasse 100, Zurich 809I,

Switzerland

Email malcolm.kohler@usz.ch
Objective: To evaluate the clinical implementation of pharmacotherapy recommendations for chronic obstructive pulmonary disease (COPD) based on the Global Initiative for chronic obstructive lung disease (GOLD) guidelines, in a longitudinal setting.

Methods: This is a sub-analysis of a prospective, non-interventional cohort study including patients with confirmed mild-to-very-severe COPD from seven pulmonary outpatient clinics in Switzerland. Follow-up visits took place annually for up to 7 years, from October 2010 until December 2016. For each visit, we evaluated the compliance of the prescribed pharmacotherapy with the concurrently valid GOLD guideline. We investigated whether step-ups or step-downs in GOLD stage or risk-group were accompanied by concordant changes in prescribed medication. Groups were compared via ANOVA.

Results: Data of 305 patients (62 \pm 7 years, $66 \%$ men) were analysed. In $59.1 \%$ of visits, the prescribed medication conformed to the respective valid GOLD-guideline. Patients with very severe COPD were most likely to receive pharmacotherapy in compliance with guidelines. Step-ups and step-downs in risk group, requiring escalation, or de-escalation of pharmacotherapy, were noticed in 24 and 43 follow-up visits, respectively. Step-ups were adequately implemented in $4(16.7 \%)$ and step-downs in six cases (14.0\%).

Conclusion: The compliance of COPD-pharmacotherapy with GOLD-guidelines is suboptimal, especially in lower risk groups. The high rates of missed out treatment-adjustments suggest that the familiarity of physicians with guidelines leaves room for improvement.

Keywords: chronic obstructive pulmonary disease, Global Initiative for Chronic Obstructive Lung Disease guidelines, guideline-compliance

\section{Plain Language Summary}

Treatment of chronic obstructive lung disease (COPD) in line with the recommendations of the Global Initiative for Chronic Obstructive Lung Disease (GOLD) guideline has been shown to improve the patient's quality of life and to decrease healthcare costs. However, the compliance of prescribed pharmacotherapy to GOLD guidelines appears to be suboptimal, according to crosssectional studies. We evaluated the conformity of pharmacotherapy with GOLD guidelines in a longitudinal study, investigating a Swiss cohort of patients with COPD. We found the pharmacotherapy regimens in our cohort to be only partially compliant with guidelines, most commonly due to overtreatment with inhaled corticosteroids, but also overtreatment with or a lack of bronchodilator-treatment was observed frequently. Furthermore, longitudinal changes in therapyregimens that would had been necessary according to GOLD guidelines were rarely implemented correctly. We, therefore, conclude that the guideline-conformity of COPD treatment yet leaves considerable room for improvement, in order to achieve optimal symptom reduction in each patient. 


\section{Introduction}

Chronic obstructive pulmonary disease (COPD), with a global prevalence of approximately $11.7 \%$, is considered the fourth leading cause of death worldwide. ${ }^{1,2}$ COPD is associated with a significant economic burden, producing annual costs of nearly 50 billion Euros in the European Union. $^{3}$ The Global Initiative for Chronic Obstructive Lung Disease (GOLD) strategy-guideline aims for the inclusion of concurrent therapy recommendations in clinical practice. Optimal pharmacological treatment of patients with COPD can improve symptoms, ${ }^{4-7}$ exercise capacity, ${ }^{4,6}$ health status, ${ }^{8}$ and reduces exacerbations. ${ }^{9,10}$ Accordingly, optimal implementation of GOLD-guidelines in clinical practice has been shown to significantly decrease healthcare costs. ${ }^{11}$ Whereas a lack in pharmacotherapy might impair patient and healthcare outcomes, overtreatment should be avoided as well. Especially indications for inhaled corticosteroids (ICS) have become fewer, due to their unfavourable costbenefit-ratio, with regards to serious adverse events and the superior effectiveness of long-acting bronchodilators (BD) in decreasing exacerbations. ${ }^{12}$ Despite the beneficial outcomes associated with guideline-complying therapy, various crosssectional studies showed GOLD-implementation to be suboptimal, presumably due to poor familiarity of physicians with guidelines. ${ }^{13-15}$ Additionally, substantial changes in GOLD reports published throughout the years, such as the introduction and modification of the $» \mathrm{ABCD} \ll-$ scheme in 2011 and 2017, possibly impair clinician's familiarity with the recommendations even more. Yet, due to the progressive nature of COPD, treatment regimens have to be re-evaluated at least annually. ${ }^{16}$ However, knowledge of the clinical realisation of recommended therapy adjustments in longitudinal settings is mostly lacking.

The aim of this study was to evaluate the clinical implementation of recommendations for pharmacotherapy and pharmacotherapy-adjustments based on GOLDguidelines, in a Swiss cohort of patients with mild-tovery-severe COPD.

\section{Methods}

\section{Subjects}

This is a sub-analysis of the prospective, non-interventional cohort study 'The Obstructive Pulmonary Disease Outcomes Cohort Study (TOPDOCS)'. Patients with COPD from seven pulmonary outpatient clinics in Switzerland were included in the cohort during outpatient visits or hospital stays. Follow-up visits took place annually for up to 7 years, from October 2010 until December 2016, within a mean follow-up period of 2.03 years. Patients with confirmed mild-to-very-severe COPD were eligible. Exclusion criteria were mental constraint disabling the patient to give written informed consent and to comply with the study instructions, respectively. The Ethics Committee of Zurich approved the study (EK-ZH-NR: 1734 and 2011-0106), which was conducted in accordance with the declaration of Helsinki and which was registered at www. ClinicalTrials.gov, NCT01527773.

\section{Measurements}

The following factors were assessed annually.

\section{Comorbidities, Symptoms and Health Status}

Interviews, clinical examinations, and reviews of the medical history were performed. COPD-associated symptoms and their impact on health were evaluated by means of COPD Assessment testing (CAT). ${ }^{17}$ The severity of dyspnoea was assessed with the help of the modified medical research council (mMRC) scale. ${ }^{18}$ Acute exacerbations (AE) were defined as an increase in dyspnoea, cough and/or sputum production, requiring treatment with antibiotics and/or oral corticosteroids. Participants were classified as frequent exacerbators when at least two-, and as infrequent exacerbators when less exacerbations occurred during the respective previous year.

\section{Respiratory Variables}

Forced expiratory volume in one second (FEV1), residual volume to total lung capacity (RV/TLC), and diffusing capacity of the lung for carbon monoxide (DLco) were measured after bronchodilation within a standard pulmonary functioning test, performed in accordance with guidelines of the American Thoracic Society and the European Respiratory Society. ${ }^{19,20}$ Participants were categorised into GOLD stages (I-IV), and risk groups (A-D) consistent with the respective concurrent guideline at each visit. ${ }^{12,21,22}$

\section{Medication and Accordance with Guidelines}

For each visit, we evaluated the conformity of prescribed pharmacotherapy with the respective, concurrently valid GOLD guideline. The study started in 2010; thus, the valid guideline for the 2010 visits was the 2006 GOLD report. Within the course of the trial, changes in guidelines with an impact on treatment recommendations were published in the 2011 revision and the 2014 update. $^{21,22}$ Identifying overtreatment in line with the GOLD recommendation-table is quite distinct (figure 5.3-7 in guideline 2007, figure 4.4 in guidelines 2011 and 2014). ${ }^{12,21,22}$ For instance, patients in risk-group A or 
$\mathrm{B}$ receiving ICS are clearly overtreated. However, more careful considerations are required when defining undertreatment, as, for example, GOLD A patients who do not receive medical treatment are not necessarily undertreated. According to GOLD, a lack of bronchodilator (BD) treatment is only present when the patient receives no such drug despite being symptomatic. Therefore, only symptomatic patients (mMRC-score $\geq 2$ or CAT-score $\geq 10$ ) who did not receive an inhaled BD were classified undertreated. The 2006 report recommends adding ICS in patients with GOLD stage III and IV, who have repeated exacerbations; thus, these criteria were adopted for defining ICS undertreatment in visits before 2011. In line with GOLD 2011 and 2014, from 2011 on, patients not receiving ICS were defined as ICS undertreated when they were categorised GOLD stage III or IV and had exacerbations frequently $(\geq 2$ per year), despite treatment with long-acting BDs. The absence of roflumilast was not rated as undertreatment, since the recommendation for this agent is rather weak. GOLD-2011 and 2014 state that it may be added in stage III or IV patients with frequent exacerbations that are not adequately controlled by long-acting BDs. However, roflumilast prescribed to patients with GOLD stage I or II was defined as overtreatment from 2011 on.

\section{Changes in Recommended Medication Over Time and Influence of Guideline Changes}

We investigated whether step-ups or step-downs in GOLD stage or risk-group were accompanied by adequate changes in prescribed medication. Furthermore, we longitudinally analysed individual changes in therapy-recommendations, which were conditioned exclusively by guideline change. Therefore, whenever a step-up or -down in risk-group was noticed in a visit following a change in the guideline, the respective recommendation was compared to what would have been recommended in the former guideline, for the specific case. Furthermore, we applied the categorisation criteria from GOLD 2017 on our cohort for investigating the impact of this guideline on individual treatment-suggestions. In the 2017 GOLD report, the »ABCD«-system was significantly modified, as airway obstruction was excluded from the categorisation criteria.

\section{Statistical Analysis}

Descriptive statistics include mean and standard deviation (SD) for normally distributed parameters, as well as median and $25 \% / 75 \%$-quartiles for non-normally distributed variables. Categorical variables are shown as numbers and percentages of the total. For continuous variables, groups (correct treatment vs undertreatment vs overtreatment vs varying treatment) were compared via ANOVA. For posthoc testing, one-way ANOVA was used. P-values were Bonferroni corrected. Categorical variables were assessed by Chi-squared test. A two-sided p-value of $<0.05$ was considered to be statistically significant. We used STATA/ SE15.1 (StataCorp, College Station, TX, USA) for analysis.

\section{Results}

\section{Participants}

Three hundred and twenty-six patients initially gave consent and data of 305 participants (726 study-visits) were available for analysis (Figure 1). See Table 1 for baseline characteristics.

\section{Implementation of GOLD Recommendations}

A $8.8 \%$ of visits fell under the scope of the $2006,54.3 \%$ of the 2011 , and $36.9 \%$ of the 2014 GOLD-guidelines. In

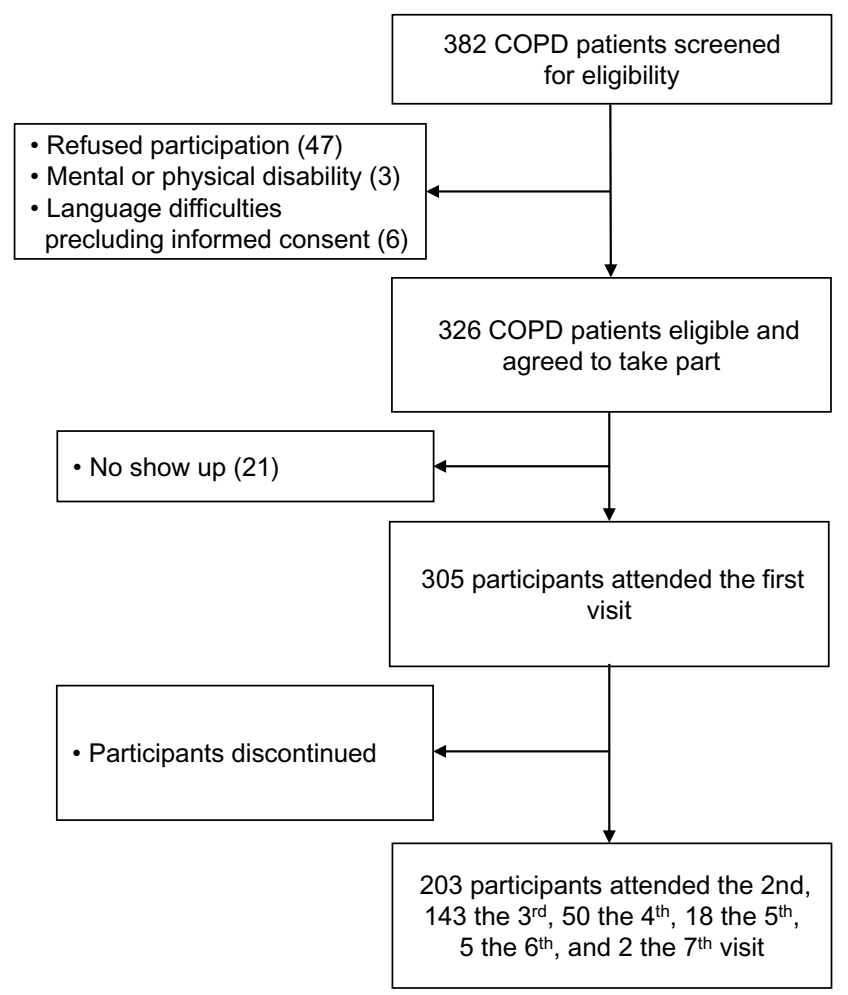

Figure I Study flow. The decrease in the number of participants has several reasons: the cohort-study was initially designed as a cross-sectional trial. During the course of the first year, the design was changed to a longitudinal study intended to analyse the course of lung function, exacerbations, cardiovascular outcomes, and further parameters over a period of 3 years. The participants gave consent to only one study visit initially and, when asked again after the first year, a great number of participants did not agree to taking part in a 3-year-study. Then again, after 3 years, the study period was extended and only a part of the participants agreed to continue. Additionally, parts of the initial COPD-cohort had died within the study period. 
Table I Baseline Characteristics

\begin{tabular}{|c|c|}
\hline \multicolumn{2}{|l|}{ Clinical Characteristics } \\
\hline Age, years & $62.3(7.3)$ \\
\hline Male, n/total (\%) & $201 / 305(65.90 \%)$ \\
\hline BMI, $\mathrm{kg} / \mathrm{m}^{2}$ & $26(22.5 / 29.4)$ \\
\hline Smoker, n/total (\%) & $231 / 305(75.74 \%)$ \\
\hline Pack years, $n$ & $40(30 / 60)$ \\
\hline GOLD stage I, n/total (\%) & $26 / 305(8.52 \%)$ \\
\hline GOLD stage $2, \mathrm{n} /$ total (\%) & $100 / 305(32.79 \%)$ \\
\hline GOLD stage $3, \mathrm{n} /$ total (\%) & III/305 (36.39\%) \\
\hline GOLD stage $4, \mathrm{n} /$ total (\%) & $68 / 305(22.30 \%)$ \\
\hline mMRC-Score, $n$ & $1.73(1.06)$ \\
\hline CAT-Score, $\mathrm{n}$ & $16(7.24)$ \\
\hline FEVI post dilatation, $\%$ predicted & $44(3 \mid / 64.2)$ \\
\hline RV/TLC, \% predicted & $55.27(11.84)$ \\
\hline $\mathrm{DL}_{\mathrm{CO}}(\mathrm{Hb}), \%$ predicted & $47(35 / 68)$ \\
\hline Exacerbations in previous year, $\mathrm{n}$ & $\mathrm{I}(0 / 2)$ \\
\hline $\begin{array}{l}\text { Exacerbations in previous year leading to } \\
\text { hospitalisation, } n\end{array}$ & $0(0 / 0)$ \\
\hline Frequent exacerbator, n/total (\%) & $77 / 305(25.25 \%)$ \\
\hline
\end{tabular}

Notes: Values are presented as Mean (SD) or Median (IQR), unless stated otherwise. Abbreviations: BMI, Body Mass Index; GOLD, Global Initiative for Obstructive Lung Disease; mMRC, Modified British Medical Research Council; CAT, Chronic Obstructive Pulmonary Disease Assessment Test; FEVI, Forced expiratory volume in I second; RV/TLC, Residual volume/total lung capacity; $\mathrm{DL}_{\mathrm{CO}}(\mathrm{Hb})$, Carbon monoxide diffusion capacity for haemoglobin concentration.

$59.1 \%$ of visits, the prescribed medication conformed to the concurrent recommendations, $61.8 \%$ and $59.0 \%$ before and after the introduction of risk-groups in 2011, respectively. GOLD non-compliant therapy was due to overtreatment with ICS in $40.7 \%$, with long-acting BD in $9.8 \%$, with ICS and long-acting BD in $1.5 \%$, and due to undertreatment with ICS, BD, or ICS and long-acting BD, in $17.1 \%, 16.7 \%$, and $1.5 \%$ of cases, respectively. The distribution of pharmacotherapies and the accordance with GOLD-guidelines are shown before and after the introduction of symptom-based categories in 2011 (Tables 2 and 3, Figure 2A and B).

\section{Adjustments of Treatment Regimens to Worsening of COPD and Guideline-Change}

Step-ups and -downs in risk-category requiring escalation, or de-escalation of pharmacotherapy were noticed in 24, and 43 follow-up visits, respectively. Steps-ups were adequately implemented in $4(16.7 \%)$, steps down in 6 cases $(14.0 \%)$, after a mean period of 1.1 visits. Participants whose therapy was adjusted in line with recommendations were categorised risk-group $\mathrm{A}$ in $30 \%, \mathrm{~B}$ in $20 \%, \mathrm{C}$ in $10 \%$, and $\mathrm{D}$ in $40 \%$. Cases in which adequate therapy-adjustments were missed out were followed for 1.6 visits in mean. None of the observed
Table 2 Overview on Medication of the Cohort, and Accordance with 2006 GOLD Guideline (Visits That Took Place Before 201 I)

\begin{tabular}{|c|c|c|c|c|}
\hline GOLD Stage & $\mathbf{I}$ & II & III & IV \\
\hline \multicolumn{5}{|c|}{ Prescribed medication of cohort } \\
\hline No treatment & $57.1 \%$ & $52.9 \%$ & $4.8 \%$ & $0.0 \%$ \\
\hline LAMA & $28.6 \%$ & $5.9 \%$ & $4.8 \%$ & $5.0 \%$ \\
\hline LAMA+ICS & $0.0 \%$ & $0.0 \%$ & $4.8 \%$ & $5.0 \%$ \\
\hline$L A B A+I C S$ & $14.3 \%$ & $17.6 \%$ & $4.8 \%$ & $5.0 \%$ \\
\hline$L A M A+L A B A$ & $0.0 \%$ & $0.0 \%$ & $4.8 \%$ & $5.0 \%$ \\
\hline$L A M A+L A B A+I C S$ & $0.0 \%$ & $23.5 \%$ & $66.7 \%$ & $70.0 \%$ \\
\hline LABA+ICS+THEO & $0.0 \%$ & $0.0 \%$ & $4.8 \%$ & $5.0 \%$ \\
\hline LAMA+LABA+ICS+THEO & $0.0 \%$ & $0.0 \%$ & $4.8 \%$ & $5.0 \%$ \\
\hline$\%$ of total visits & $10.8 \%$ & $26.2 \%$ & $32.3 \%$ & $30.8 \%$ \\
\hline \multicolumn{5}{|c|}{ Accordance with GOLD 2006} \\
\hline $\begin{array}{l}\% \text { treatment according to } \\
\text { guideline }\end{array}$ & $25 \%$ & $33.3 \%$ & $78.6 \%$ & $85.7 \%$ \\
\hline \multicolumn{5}{|l|}{ Undertreatment } \\
\hline Short-acting BD & $25 \%$ & $0.0 \%$ & $0.0 \%$ & $0.0 \%$ \\
\hline Short and long-acting BD & $0.0 \%$ & $33.3 \%$ & $0.0 \%$ & $0.0 \%$ \\
\hline ICS & $0.0 \%$ & $0.0 \%$ & $0.0 \%$ & $14.3 \%$ \\
\hline \multicolumn{5}{|l|}{ Overtreatment } \\
\hline Long-acting BD & $50 \%$ & $0.0 \%$ & $0.0 \%$ & $0.0 \%$ \\
\hline ICS & $0.0 \%$ & $22.2 \%$ & $21.4 \%$ & $0.0 \%$ \\
\hline Long-acting BD and ICS & $0.0 \%$ & $11.1 \%$ & $0.0 \%$ & $0.0 \%$ \\
\hline
\end{tabular}

Notes: Values are presented as percentage of the respective stage of disease, separately for the prescribed medicine, and the accordance with guidelines, respectively.

Abbreviations: GOLD, Global Initiative for Chronic Obstructive Lung Disease; SABA, short-acting $\beta 2$-receptor agonist; LAMA, long-acting muscarinic antagonist; ICS, inhaled corticosteroid; LABA, long-acting $\beta 2$-receptor agonist; ROFL, Roflumilast; THEO, Theophylline; BD, Bronchodilator.

steps occurred exclusively due to a change in the guideline. However, when categorising our cohort after the GOLD2017-criteria, $44.20 \%$ of participants would be shifted from group $\mathrm{D}$ to $\mathrm{B}$, and $6.2 \%$ from group $\mathrm{C}$ to $\mathrm{A}$ or $\mathrm{B}$.

\section{Comparison of Characteristics Between Groups}

A comparison of characteristics between participants who were correctly-, under-, over-, or variably treated throughout all visits can be seen in Table 4. The group of steadily undertreated participants had a significantly higher bodymass-index (BMI), and contained the largest amount of smokers, when compared with the rest of the cohort. Compliantly treated participants had the significantly highest mMRC and CAT scores, lowest FEV1 and DLco and highest RV/TLC values of all groups. Among under- and overtreated 
Table 3 Overview on Medication of the Cohort, and Accordance with GOLD 20II/20I4 (Visits from 20II on)

\begin{tabular}{|c|c|c|c|c|}
\hline Risk Group & $\mathbf{A}$ & B & C & $\mathbf{D}$ \\
\hline \multicolumn{5}{|c|}{ Prescribed medication of cohort } \\
\hline No treatment & $43.8 \%$ & $29.2 \%$ & $3.8 \%$ & $2.3 \%$ \\
\hline SABA & $6.9 \%$ & $1.2 \%$ & $1.7 \%$ & $0.3 \%$ \\
\hline LAMA & $11.5 \%$ & $17.6 \%$ & $5.1 \%$ & $2.8 \%$ \\
\hline LAMA+ICS & $0.0 \%$ & $0.0 \%$ & $0.0 \%$ & $1.2 \%$ \\
\hline LABA & $3.8 \%$ & $4.7 \%$ & $1.7 \%$ & $0.6 \%$ \\
\hline$L A B A+I C S$ & $13.1 \%$ & $15.9 \%$ & $15.3 \%$ & $9.8 \%$ \\
\hline LAMA+LABA & $6.2 \%$ & $5.9 \%$ & $16.9 \%$ & $8.3 \%$ \\
\hline$L A M A+L A B A+I C S$ & $13.8 \%$ & $28.2 \%$ & $45.8 \%$ & $63.5 \%$ \\
\hline LAMA+ICS+ROFL & $0.0 \%$ & $0.0 \%$ & $0.0 \%$ & $0.6 \%$ \\
\hline LAMA+LABA+ROFL & $0.0 \%$ & $0.6 \%$ & $0.0 \%$ & $0.6 \%$ \\
\hline LAMA+LABA+ICS+ROFL & $0.8 \%$ & $2.4 \%$ & $3.4 \%$ & $9.2 \%$ \\
\hline LABA+ICS+THEO & $0.0 \%$ & $0.6 \%$ & $0.0 \%$ & $0.6 \%$ \\
\hline LAMA+LABA+THEO & $0.0 \%$ & $0.0 \%$ & $0.0 \%$ & $0.3 \%$ \\
\hline LAMA+LABA+ICS+THEO & $0.0 \%$ & $0.6 \%$ & $1.7 \%$ & $1.2 \%$ \\
\hline$\%$ of total visits & $19 \%$ & $24.8 \%$ & $8.6 \%$ & $47.6 \%$ \\
\hline \multicolumn{5}{|c|}{ Accordance with GOLD $2011 / 14$} \\
\hline $\begin{array}{l}\text { \%treatment according to } \\
\text { guideline }\end{array}$ & $65.9 \%$ & $30.0 \%$ & $38.6 \%$ & $76.1 \%$ \\
\hline \multicolumn{5}{|l|}{ Undertreatment } \\
\hline $\mathrm{BD}$ & $0.0 \%$ & $22.4 \%$ & $0.0 \%$ & $0.0 \%$ \\
\hline ICS & $0.0 \%$ & $0.0 \%$ & $14.0 \%$ & $11.7 \%$ \\
\hline Long-acting $\mathrm{BD}$ and ICS & $0.0 \%$ & $0.0 \%$ & $0.0 \%$ & $1.2 \%$ \\
\hline \multicolumn{5}{|l|}{ Overtreatment } \\
\hline Long-acting BD & $9.4 \%$ & $0.0 \%$ & $28.1 \%$ & $0.0 \%$ \\
\hline GC & $20.0 \%$ & $45.3 \%$ & $5.3 \%$ & $0.0 \%$ \\
\hline Long-acting BD and ICS & $3.5 \%$ & $0.0 \%$ & $0.0 \%$ & $0.0 \%$ \\
\hline ROFL & $0.0 \%$ & $0.6 \%$ & $0.0 \%$ & $0.0 \%$ \\
\hline $\begin{array}{l}\text { Overtreatment, categories not } \\
\text { applicable }\end{array}$ & $1.2 \%$ & $1.8 \%$ & $14.0 \%$ & $9.8 \%$ \\
\hline \multicolumn{5}{|l|}{ Other } \\
\hline $\begin{array}{l}\text { Incorrect treatment, over or } \\
\text { undertreatment not applicable }\end{array}$ & $0.0 \%$ & $0.0 \%$ & $0.0 \%$ & $0.6 \%$ \\
\hline
\end{tabular}

Notes: Values are presented as percentage of the respective stage of the disease, separately for the prescribed medicine, and the accordance with guidelines, respectively.

Abbreviations: GOLD, Global Initiative for Chronic Obstructive Lung Disease; SABA, short-acting $\beta 2$-receptor agonist; LAMA, long-acting muscarinic antagonist; ICS, inhaled corticosteroid; LABA, long-acting $\beta 2$-receptor agonist; ROFL, Roflumilast; THEO, Theophylline; BD, Bronchodilator.

participants, there were significantly less frequent exacerbators, when compared with the correctly treated patients.

\section{Discussion}

This study evaluated the conformity of COPDpharmacotherapy and therapy adjustments, with GOLD guidelines. To our knowledge, no previous trial classified under- and overtreatment-categories in this detail. We found that the prescribed medications were only partially compliant with guidelines. Furthermore, required escalations and de-escalations of pharmacotherapy were inadequately realised. Patients with more severe COPD were more likely to be treated in accordance with guidelines.

Whereas COPD is not curable, it is yet a treatable condition. Pharmacological treatment is a fundamental component of COPD therapy, as it has been shown to improve the patient's quality of life, ${ }^{23}$ when administered in accordance with treatment recommendations. However, previous studies suggested discrepancies between prescribed medication and guideline-propositions. The rather low rate of guidelineadherent therapy prescribed in our cohort (59.1\%) is in line with the results of earlier studies. ${ }^{14,24}$ Factors that might explain the low conformity-rates, next to inadequate familiarity with guidelines, might be time-constraints or low selfefficacy of physicians. ${ }^{25}$ Educational interventions to improve physician's familiarity with guidelines have been shown to be successful; thus, their utilisation should be further promoted. ${ }^{25,26}$ In this study, ICS over-prescription was the most common reason for guideline non-compliance. This finding is quite alarming, as serious side-effects of ICS, such as pneumonia, could be avoided. ${ }^{27}$ Especially in combination with long-acting muscarinic antagonists (LAMA) and longacting $\beta 2$-receptor agonists (LABA), ICS over-prescription was observed in other populations with COPD as well. ${ }^{14,28}$ Inhaled BDs are effective in reducing dyspnoea and exacerbations, and they show a comparably favourable tolerability over ICS. However, particularly cardiac arrhythmia and tremor are adverse effects that have to be taken into account when prescribing inhaled BDs without impeccable indications. Nevertheless, we also found large amounts of patients that were BD-undertreated. Due to their alleviating effects on dyspnoea and their potential to reduce exacerbations, treatment with BDs is of central importance in COPD. ${ }^{16,29}$ Yet, with regard to our results, the rate of patients treated with inhaled BDs is improvable.

Required escalations, or de-escalations in pharmacotherapy were rarely implemented correctly within our cohort. This finding calls into question the physician's familiarity with guidelines and their routine in classifying disease severity and establishing treatment regimens. In a survey reported by Palmiotti et al, ${ }^{14} 60 \%$ of pulmonologists stated that the categorisation into the $» \mathrm{ABCD}$ «-groups was cumbersome in clinical practice, as performing spirometry at each visit would take too long. However, the conformity of prescribed 
A

A

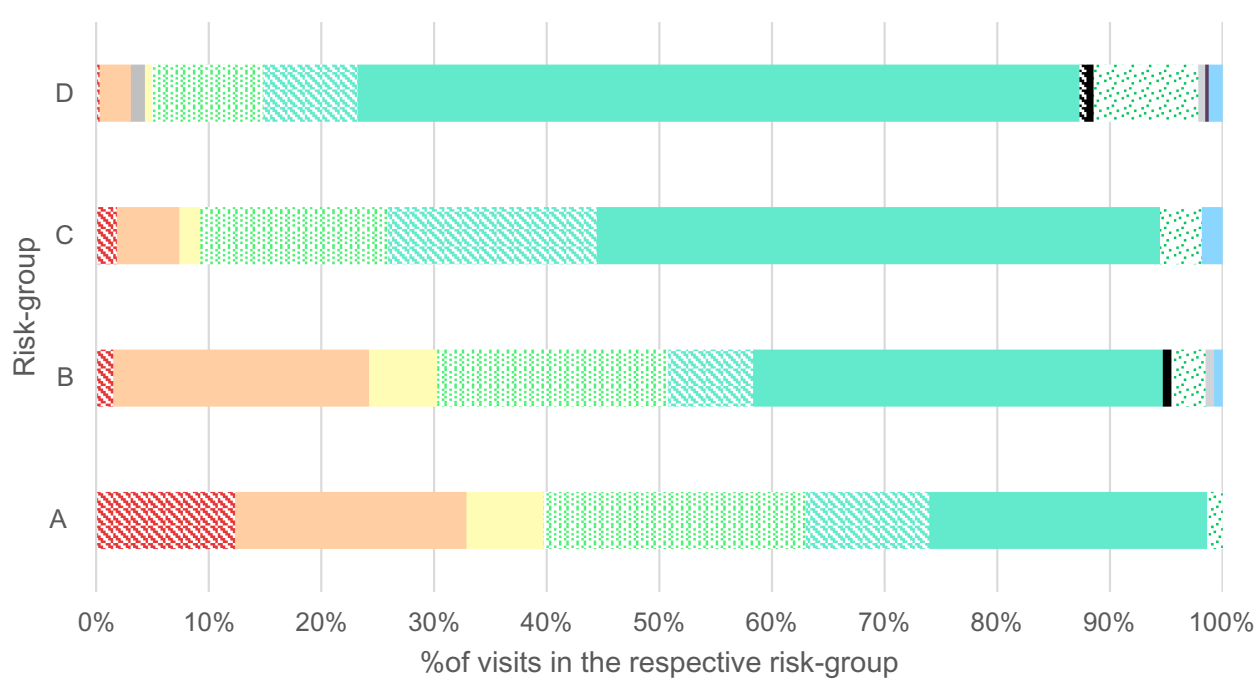

SABA

- LAMA

- LAMA+ICS

LABA

8: LABA+ICS

$\triangle$ LAMA+LABA

- LAMA+LABA+ICS

- LAMA+ICS+ROFL

- $\angle A M A+\angle A B A+R O F L$

$\therefore$ LAMA+LABA+ICS+ROFL

- LABA+ICS+THEO

- LAMA+LABA+THEO

B

$$
\text { - LAMA+LABA+ICS+THEO }
$$

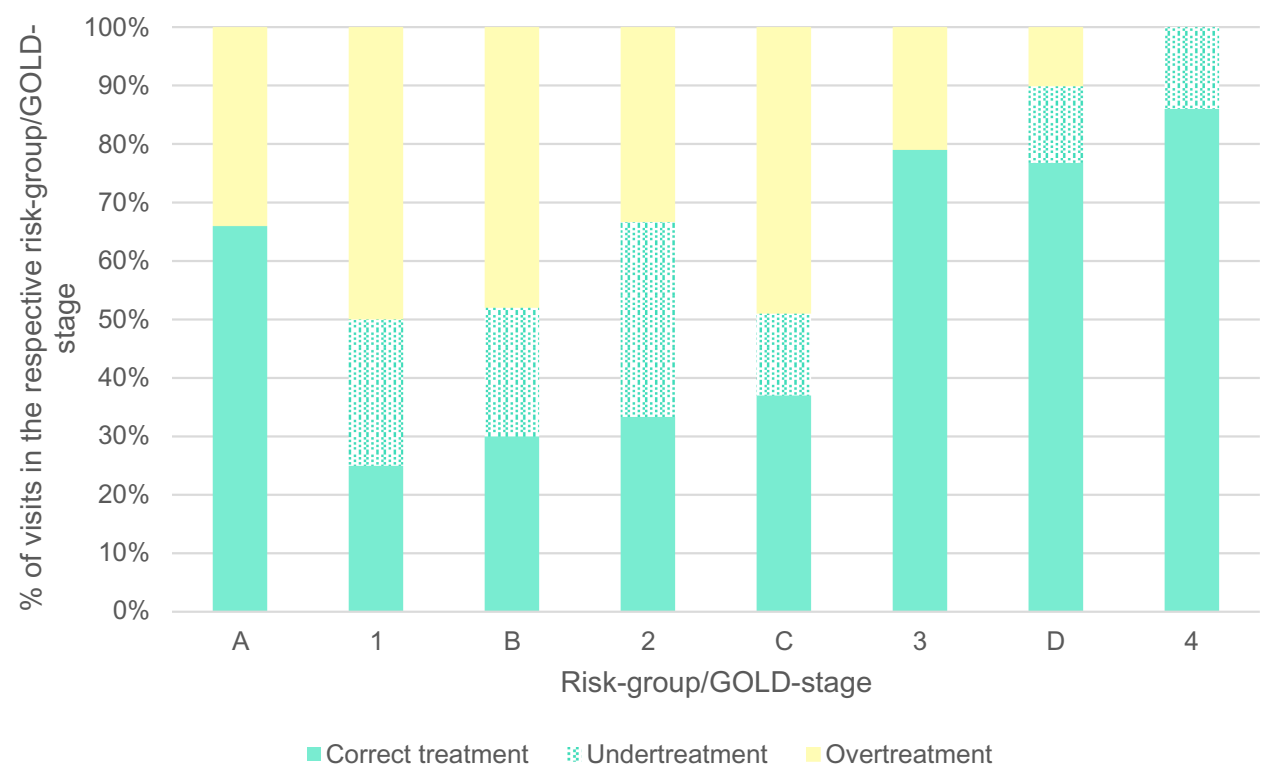

Figure 2 Distribution of prescribed medication and accordance with guidelines. (A) By risk-category: distribution of prescribed medicine. Nineteen percent of participants were categorised group A, 24.8\% B, 8.6\% C, and 47.6\% D. Visits, in which the patient had no medication were not depicted in (A) due to clarity reasons. (B) By GOLD-stage (visits before $201 \mathrm{I}$ ), or risk-category (visits from $20 \mathrm{II}$ on): amount of visits where correct treatment, undertreatment, and overtreatment was observed. In visits before $20 \mathrm{II}$, I $2 \%$ of patients were GOLD-stage I, $26 \%$ stage 2, $41 \%$ stage 3, and $21 \%$ stage 4 . In visits from 201 I on, $19 \%$ of participants were categorised group A, $24.8 \%$ B, $8.6 \%$ C, and $47.6 \%$ D.

Abbreviations: SABA, short-acting $\beta 2$-receptor agonist; LAMA, long-acting muscarinic antagonist; ICS, inhaled corticosteroid; LABA, long-acting $\beta 2$-receptor agonist; ROFL, Roflumilast; THEO, Theophylline; BD, Bronchodilator.

medication with guidelines was similar before and after the introduction of the $» \mathrm{ABCD} \ll$-system in our cohort. Further changes in GOLD-guidelines that were published within our follow-up period had no effects on the individual treatment recommendations of our cohort. Nevertheless, fundamental changes in patient categorisation were published in the 2017 GOLD report, where disease-severity assessed by spirometry was excluded from the $» \mathrm{ABCD} \ll-$-classification-criteria. In line with the results of Cabrera López et al, ${ }^{30}$ the majority of participants in our study would have been shifted into 
Table 4 Comparison of Clinical Characteristics Between Groups

\begin{tabular}{|c|c|c|c|c|c|}
\hline Baseline $(N=306)$ & $\begin{array}{l}\text { Correct Treatment } \\
N=161\end{array}$ & $\begin{array}{l}\text { Undertreatment } \\
\mathrm{N}=35\end{array}$ & $\begin{array}{l}\text { Overtreatment } \\
N=35\end{array}$ & $\begin{array}{l}\text { Varying Treatment } \\
\mathrm{N}=\mathbf{7 4}\end{array}$ & $\begin{array}{l}\text { Overall } \\
\text { p-value }\end{array}$ \\
\hline Median age, years & $64(58 / 69)$ & $62(54 / 68.5)$ & $63(52.67 / 68)$ & $65.5(61.5 / 70)$ & 0.017 \\
\hline Median body-mass-index, $\mathrm{kg} / \mathrm{m}^{2}$ & $24.2(21.03 / 28.37)$ & $28.6(25.11 / 33.89)^{*}$ & $26.53(23.2 / 28.72)^{\dagger}$ & $26.035(22.9 / 28.9)^{\dagger}$ & $<0.001$ \\
\hline Female/male sex (\%female) & $57 / 104(35.40 \%)$ & $6 / 29(17.14)$ & $|4 / 2|(40.00 \%)$ & $27 / 47(36.49 \%)$ & 0.149 \\
\hline $\begin{array}{l}\text { Non-smoker/smoker at baseline }(\% \\
\text { non-smoker) }\end{array}$ & $|30 / 3|(80.75 \%)$ & $19 / 16 *(54.29 \%)$ & $25 / 10(71.43 \%)$ & $57 / 17^{\dagger}(77.03 \%)$ & 0.010 \\
\hline Median mMRC-score, $n$ & $2(1.5 / 3)$ & $0(1 / 1.5)^{*}$ & I $(0.5 / 2)^{*}$ & $\mathrm{I}(\mathrm{I} / 2)^{*}$ & $<0.001$ \\
\hline Median CAT-score, $n$ & $18(14 / 22)$ & $12(7 / 14.5)^{*}$ & $13(7 / 19)^{*}$ & $13(9 / 20)^{*}$ & $<0.001$ \\
\hline $\begin{array}{l}\text { Median FEVI post dilation, } \% \\
\text { predicted }\end{array}$ & $34(25 / 43.5)$ & $73(55 / 82)^{*}$ & $61(43 / 74)^{*}$ & $55.5(43 / 69)^{* \dagger}$ & $<0.001$ \\
\hline Median RV/TLC, \% & $62(54 / 68)$ & $42.75(37 / 49)^{*}$ & $49(4 \mid / 58)^{*}$ & $51.87(46 / 59.5)^{* \dagger}$ & $<0.001$ \\
\hline Median DLco, $\mathrm{mmol} / \mathrm{kPa} / \mathrm{min}$ & $36(29 / 50)$ & $72.5(59 / 83.5)^{*}$ & $53(38 / 69)^{* \dagger}$ & $56.5(4|.5 / 7|)^{* \ddagger}$ & $<0.001$ \\
\hline $\begin{array}{l}\text { Frequent exacerbator at baseline, no/ } \\
\text { yes }(\% \text { no) }\end{array}$ & $109 / 52(67.70 \%)$ & $33 / 2 *(94.29 \%)$ & $3 \mathrm{l} / 4 *(88.57 \%)$ & $55 / 19^{\dagger}(74.32 \%)$ & 0.002 \\
\hline
\end{tabular}

Notes: * $\mathrm{p}<0.05$ vs "correct treatment"; ${ }^{\dagger} \mathrm{p}<0.05$ vs "undertreatment", ${ }^{\ddagger} \mathrm{p}<0.05$ vs "overtreatment". Variables are presented as mean (SD) or Median (IQR) unless otherwise stated.

Abbreviations: mMRC, Modified British Medical Research Council; CAT, chronic obstructive pulmonary disease Assessment Test; FEVI, Forced Expiratory Volume; RV, Residual Volume; TLC, Total Lung Capacity; DLco, Diffusion factor of the Lung for Carbon Monoxide.

other groups with application of the GOLD 2017-system, mostly from groups $\mathrm{C}$ to $\mathrm{A}$ or $\mathrm{B}$, and group $\mathrm{D}$ to $\mathrm{B}$. This reclassification causes even greater amounts of patients to be overtreated with ICS. In connection with the low rates of correctly performed therapy adjustments noticed in our cohort, this result suggests that great amounts of patients are still ICS overtreated in 2019. However, whether ICS therapy should be discontinued in these patients is currently under discussion, since ICS withdrawal might be associated with increases in symptoms and exacerbations. ${ }^{16}$

We observed that patients who were undertreated throughout all study-visits, had the significantly highest BMI, when compared with the rest of the cohort. We assume that in more obese patients, COPD-severity is likely to be underrated, as overweight itself is a prevalent cause of dyspnoea and wheezing. ${ }^{31}$ Thus, physicians might underestimate the actual need for COPD-treatment in obese patients. The comparably large amount of smokers within the undertreated group may be a result of these patients' lower therapy motivations. Besides that, the physician in charge might prompt patients to stop smoking before further escalating pharmacotherapy. Participants treated in compliance with guidelines were most likely to have worse symptom-scores, lung function parameters, and frequent exacerbations. Furthermore, group D-patients were most likely to be treated guideline-compliantly in our study. Accordingly, in a COPDcohort in Hong Kong, correctly treated patients had more exacerbations when compared with under- and overtreated groups. ${ }^{24} \mathrm{We}$, therefore, presume that firstly, due to their increased symptoms and exacerbations, patients with more severe COPD have a higher probability to be treated in hospitals, and therefore by specialists. Secondly, these patients experience more disease burden, and therefore might put more effort into their own therapy. Lastly, GOLDguidelines offer the greatest amount of combinations for medical therapy in risk-group $\mathrm{D}$, thereby increasing the chance to administer a correct treatment.

A limitation of our study is that we did not collect data on the respective physician in charge. Secondly, since the termination of the investigated follow-up-period, important changes in GOLD-guidelines have been published. Nevertheless, our main outcome was the guidelineconformity of therapy-adjustments, which presumably has not changed since 2016. Thirdly, we cannot be sure if every participant had seen the respective physician in charge once yearly, even if yearly follow-up is recommended in GOLD-guidelines. Fourthly, the medication prescribed is not necessarily identical to the medication the patient actually is on. However, information on the respective pharmacotherapy regimen of the individual participants was acquired by asking the patients for the medication they concurrently take. Lastly, we did not ask the respective physicians in charge whether they followed GOLD or other guidelines. Yet, our main outcome was to investigate the accordance of COPD-pharmacotherapy in Switzerland with the international state-of-the-art, rather than the ability of the respective physicians in charge to implement the guidelines they intended to follow. 


\section{Conclusions}

In conclusion, we found only partial compliance of COPD-pharmacotherapy with GOLD-guidelines. Overtreatment with ICS appears to be the most common therapeutic error, and it is an increased issue nowadays, as indications for ICS have become fewer. However, also undertreatment due to absence of inhaled BDs was frequently noticed in our cohort. As BDs depict the backbone of COPD treatment, enhancing the supply with these agents should be focused. The poor guideline-conformity of treatment-adjustments suggests that the familiarity of physicians with guidelines is insufficient and leaves room for improvement. Particularly pharmacotherapy of patients in lower GOLD stages seems to be suboptimal and thus requires more attention.

\section{Abbreviations}

BMI, Body Mass Index; CAT, Chronic Obstructive Pulmonary Disease Assessment Test; COPD, Chronic obstructive pulmonary disease; $\mathrm{DL}_{\mathrm{CO}}(\mathrm{Hb})$, Carbon monoxide diffusion capacity for haemoglobin concentration; FEV1, Forced expiratory volume in 1 second; GOLD, Global Initiative for Chronic Obstructive Lung Disease; ICS, Inhaled corticosteroid; LABA, Long-acting $\beta 2$-receptor agonists; LAMA, Long-acting muscarinic antagonists; mMRC, Modified British Medical Research Council; ROFL, Roflumilast; RV/TLC, Residual volume/ total lung capacity; SABA, Short-acting $\beta 2$-receptor agonists; THEO=Theophylline; TOPDOCS, The Obstructive Pulmonary Disease Outcomes Cohort Study.

\section{Data Sharing Statement}

We do not intend to share the study data.

\section{Ethics and Consent Statement}

The Ethics Committee of Zurich approved the study (EK-ZH -NR: 1734 and 2011-0106), which was conducted in accordance with the declaration of Helsinki and which was registered at www.ClinicalTrials.gov, NCT01527773. All patients gave written informed consent before participation.

\section{Acknowledgments}

This study was supported by Lunge Zurich, Lung league of both Basel, Gottfried and Julia Bangerter-Rhyner foundation, Freiwillige Akademische Gesellschaft Basel, Lung league of Canton Thurgau, Lung league of Canton St.
Gallen, Lung league of Canton Aargau and Lung league of Canton Glarus.

\section{Disclosure}

Dr. Kohler reports personal fees from Bayer, Astra Zeneca, personal Boehringer Ingelheim, Novartis, Roche, CSL Behring, GSK, and Mundipharma, outside the submitted work, and grants from Lunge Zurich, during the conduct of the study. Dr. Clarenbach reports personal fees from Roche, from Novartis, Boehringer, GSK, Astra Zeneca, Sanofi, Vifor, and Mundipharma, outside the submitted work. All other authors report no conflicts of interest in this work.

\section{References}

1. Adeloye D, Chua S, Lee C, et al. Global and regional estimates of COPD prevalence: systematic review and meta-analysis. J Glob Health. 2015;5(2):020415. doi:10.7189/jogh.05.020415

2. Ferkol T, Schraufnagel D. The global burden of respiratory disease. Ann Am Thorac Soc. 2014;11(3):404-406. doi:10.1513/AnnalsATS. 201311-405PS

3. Website of the European Respiratory Society - European Lung White Book. Available from: https://www.erswhitebook.org/chapters/theeconomic-burden-of-lung-disease/. Accessed September 17, 2019.

4. O'Donnell DE, Lam M, Webb KA. Spirometric correlates of improvement in exercise performance after anticholinergic therapy in chronic obstructive pulmonary disease. Am J Respir Crit Care Med. 1999;160(2):542-549. doi:10.1164/ajrccm.160.2.9901038

5. ZuWallack RL, Mahler DA, Reilly D, et al. Salmeterol plus theophylline combination therapy in the treatment of COPD. Chest. 2001;119 (6):1661-1670. doi:10.1378/chest.119.6.1661

6. Belman MJ, Botnick WC, Shin JW. Inhaled bronchodilators reduce dynamic hyperinflation during exercise in patients with chronic obstructive pulmonary disease. Am J Respir Crit Care Med. 1996;153(3):967-975. doi:10.1164/ajrccm.153.3.8630581

7. COMBIVENT Inhalation Aerosol Study Group. In chronic obstructive pulmonary disease, a combination of ipratropium and albuterol is more effective than either agent alone. An 85-day multicenter trial. Chest. 1994;105(5):1411-1419. doi:10.1378/chest.105.5.1411

8. Jones PW, Bosh TK. Quality of life changes in COPD patients treated with salmeterol. Am J Respir Crit Care Med. 1997;155 (4):1283-1289. doi:10.1164/ajrccm.155.4.9105068

9. Vincken W, van Noord JA, Greefhorst AP, et al. Improved health outcomes in patients with COPD during 1 yr's treatment with tiotropium. Eur Respir J. 2002;19(2):209-216. doi:10.1183/09031936. 02.00238702

10. Casaburi R, Mahler DA, Jones PW, et al. A long-term evaluation of once-daily inhaled tiotropium in chronic obstructive pulmonary disease. Eur Respir J. 2002;19(2):217-224. doi:10.1183/09031936. 02.00269802

11. Miravitlles M, Sicras A, Crespo C, et al. Costs of chronic obstructive pulmonary disease in relation to compliance with guidelines: a study in the primary care setting. Ther Adv Respir Dis. 2013;7(3):139-150. doi: $10.1177 / 1753465813484080$

12. Rabe KF, Hurd S, Anzueto A, et al. Global strategy for the diagnosis, management, and prevention of chronic obstructive pulmonary disease. Am J Respir Crit Care Med. 2007;176(6):532-555. doi:10. 1164/rccm.200703-456SO 
13. Salinas GD, Williamson JC, Kalhan R, et al. Barriers to adherence to chronic obstructive pulmonary disease guidelines by primary care physicians. Int J Chron Obstruct Pulmon Dis. 2011;6:171-179.

14. Palmiotti GA, Lacedonia D, Liotino V, et al. Adherence to GOLD guidelines in real-life COPD management in the Puglia region of Italy. Int J Chron Obstruct Pulmon Dis. 2018;13:2455-2462.

15. Jochmann A, Neubauer F, Miedinger D, Schafroth S, Tamm M, Leuppi JD. General practitioner's adherence to the COPD GOLD guidelines: baseline data of the Swiss COPD cohort study. Swiss Med Wkly. 2010;140.

16. Singh D, Agusti A, Anzueto A, et al. Global strategy for the diagnosis, management, and prevention of chronic obstructive lung disease: the GOLD science committee report 2019. Eur Respir J. 2019;53(5):1900164. doi:10.1183/13993003.00164-2019

17. Jones PW, Harding G, Berry P, Wiklund I, Chen WH, Kline Leidy N. Development and first validation of the COPD assessment test. Eur Respir J. 2009;34(3):648-654. doi:10.1183/09031936.00102509

18. Mahler DA, Wells CK. Evaluation of clinical methods for rating dyspnea. Chest. 1988;93(3):580-586. doi:10.1378/chest.93.3.580

19. Miller MR, Hankinson J, Brusasco V, et al. Standardisation of spirometry. Eur Respir J. 2005;26(2):319-338. doi:10.1183/0903 1936.05.00034805

20. Macintyre N, Crapo RO, Viegi G, et al. Standardisation of the single-breath determination of carbon monoxide uptake in the lung. Eur Respir J. 2005;26(4):720-735. doi:10.1183/09031936.05.000 34905

21. Vestbo J, Hurd SS, Agusti AG, et al. Global strategy for the diagnosis, management, and prevention of chronic obstructive pulmonary disease: GOLD executive summary. Am J Respir Crit Care Med. 2013;187(4):347-365. doi:10.1164/rccm.201204-0596PP

22. Decramer M Global Initiative for Chronic Obstructive Lung Disease (GOLD): global strategy for the diagnosis, management and prevention of chronic obstructive pulmonary disease; 2014 [updated 2014]; Available from: http://www.goldcopd.org. Accessed March 18, 2020.
23. Alifano M, Cuvelier A, Delage A, et al. Treatment of COPD: from pharmacological to instrumental therapies. Eur Respir Rev. 2010;19 (115):7-23. doi:10.1183/09059180.00008009

24. Chan KP, Ko FW, Chan HS, et al. Adherence to a COPD treatment guideline among patients in Hong Kong. Int J Chron Obstruct Pulmon Dis. 2017;12:3371-3379. doi:10.2147/COPD.S147070

25. Perez X, Wisnivesky JP, Lurslurchachai L, Kleinman LC, Kronish IM. Barriers to adherence to COPD guidelines among primary care providers. Respir Med. 2012;106(3):374-381. doi:10.1016/ j.rmed.2011.09.010

26. Ferrara R, Ientile V, Piccinni $\mathrm{C}$, et al. Improvement in the management of chronic obstructive pulmonary disease following a clinical educational program: results from a prospective cohort study in the Sicilian general practice setting. NPJ Prim Care Respir Med. 2018;28 (1):10. doi:10.1038/s41533-018-0077-7

27. Yang IA, Fong KM, Sim EH, Black PN, Lasserson TJ. Inhaled corticosteroids for stable chronic obstructive pulmonary disease. Cochrane Database Syst Rev. 2007;2:CD002991.

28. Brusselle G, Price D, Gruffydd-Jones K, et al. The inevitable drift to triple therapy in COPD: an analysis of prescribing pathways in the UK. Int J Chron Obstruct Pulmon Dis. 2015;10:2207-2217. doi:10.2147/COPD.S91694

29. Wedzicha JA, Banerji D, Chapman KR, et al. IndacaterolGlycopyrronium versus Salmeterol-Fluticasone for COPD. $N$ Engl $J$ Med. 2016;374(23):2222-2234. doi:10.1056/NEJMoa1516385

30. Cabrera Lopez C, Casanova Macario C, Marin Trigo JM, et al. Comparison of the 2017 and 2015 Global Initiative for Chronic Obstructive Lung Disease Reports. Impact on Grouping and Outcomes. Am J Respir Crit Care Med. 2018;197(4):463-469. doi:10.1164/rccm.201707-1363OC

31. Kress JP, Pohlman AS, Alverdy J, Hall JB. The impact of morbid obesity on oxygen cost of breathing (VO(2RESP)) at rest. Am J Respir Crit Care Med. 1999;160(3):883-886. doi:10.1164/ ajrccm.160.3.9902058

International Journal of Chronic Obstructive Pulmonary Disease

Dovepress

\section{Publish your work in this journal}

The International Journal of COPD is an international, peer-reviewed journal of therapeutics and pharmacology focusing on concise rapid reporting of clinical studies and reviews in COPD. Special focus is given to the pathophysiological processes underlying the disease, intervention programs, patient focused education, and self management protocols. This journal is indexed on PubMed Central, MedLine and CAS. The manuscript management system is completely online and includes a very quick and fair peer-review system, which is all easy to use. Visit http://www.dovepress.com/testimonials.php to read real quotes from published authors. 